\title{
Caracterización y análisis de las representaciones rupestres de Aldea Beleiro, So de Chubut, Patagonia argentina
}

\section{(4) Lucía A. Gutiérrez}

Fecha de defensa: 21 de diciembre de 2020

Directora: Dra. Analía Castro Esnal

Co-directora: Lic. María Pía Falchi

Jurados: Dres. Agustín Acevedo y Anahí Re

Los estudios arqueológicos en Aldea Beleiro han tenido como objetivo entender el poblamiento de la región, la gestión de los recursos, las estrategias de movilidad y los cambios en las maneras de ocupar este espacio a lo largo del tiempo (Pérez de Micou, Castro Esnal y Sacchi, 2013; Castro Esnal, Casanueva, Sacchi y Pérez de Micou, 2016; Castro Esnal, Pérez de Micou y Casanueva, 2017; entre otros). Los trabajos realizados han dado cuenta de una ocupación humana del área desde al menos 9000 años cal. AP. No obstante, las representaciones rupestres, una línea de evidencia de importancia numérica dentro del repertorio material registrado, no habían sido trabajadas en profundidad (Gutiérrez y Pérez de Micou, 2017; Gutiérrez y Castro Esnal, 2018; Gutiérrez, Castro Esnal, Ronco, Casanueva y Pérez de Micou, 2018). En este marco, esta tesis presenta los resultados obtenidos a partir del análisis de la totalidad de motivos registrados en tres sitios de la zona: Casa de Piedra de Roselló (con sus anexos: CP1, CP2 y CP3), Cueva Alta del Portezuelo (CAP) y Pedrero de Jara (PJ) (Figura 1). Si bien se enfatizan cuestiones relacionadas con la dimensión visual, se delinean además tendencias en distintas escalas. Esta nueva información se integra con los demás aspectos de la vida social, inferidos a partir de otras líneas de evidencia recuperadas en el área.

Los objetivos e hipótesis que guiaron este trabajo fueron:

Objetivo general:

》 Contribuir al conocimiento acerca del poblamiento humano y la vida social en el sudoeste de Chubut a lo largo del Holoceno, mediante el análisis de las representaciones rupestres del área.

Objetivos específicos:

» Generar un registro detallado de las representaciones rupestres de la localidad.

* Instituto Nacional de Antropología y Pensamiento Latinoamericano (INAPL) / Facultad de Filosofía y Letras, Universidad de Buenos Aires (UBA). 3 de febrero 1378 (CP C1426BJN), Ciudad Autónoma de Buenos Aires, Argentina. E-mail: luciagutierrez94@gmail.com
» Establecer patrones para cada sitio en particular y para el área en general.

»Determinar la cronología relativa de las pinturas.

» Indagar acerca de las actividades que habrían sido realizadas en los sitios.

»Entender si existieron relaciones entre los distintos sitios con pinturas.

»Reconocer similitudes y/o diferencias con otras áreas.

Hipótesis:

" Las representaciones rupestres de Aldea Beleiro, en consonancia con lo constatado a partir de las excavaciones, reflejan un uso del área desde el Holoceno temprano hasta momentos recientes.

» La producción y el uso de pinturas rupestres en Aldea Beleiro estuvieron estrechamente relacionados con lugares de uso doméstico, con lo cual se desprende que esta tecnología habría constituido una actividad significativa y directamente vinculada a los demás aspectos de la vida económica y social.

» Las pinturas rupestres de Aldea Beleiro, en concordancia con lo postulado a partir de la evidencia lítica, reflejan relaciones con áreas cercanas y permiten inferir una circulación y/o contacto de personas entre distintos ambientes.

En función de los objetivos propuestos se trabajó en distintas escalas: sitio, microescala y mesoescala (Dincauze, 2000). De esta manera, las unidades de análisis variaron: motivo (Aschero, 1988; Gradin, 1978; Re, 2010), tipo de motivo, estilo (Aschero, 1993, 2012; Aschero e Isasmendi, 2018; Gradin, Aschero y Aguerre, 1976, 1979; Menghin, 1957) respectivamente. De acuerdo con los antecedentes disponibles, se estimó una escala temporal que abarcaría todo el Holoceno.

Durante el registro de campo se siguió la metodología sugerida por Hernández Llosas (1985) y Loendorf (2001). Posteriormente, durante el análisis de gabinete, todas las imágenes fueron procesadas y se cuantificaron y categorizaron los motivos a partir del análisis de variables descriptivas: categorías y tipos (Gradin, 1978), tonalidades, técnicas, superposiciones y visibilidad (Lenssen Erz, 2004), entre otras. Luego se realizó un procesamiento estadístico descriptivo para cumplir con los primeros objetivos.

Para la asignación cronológica de los motivos se utilizaron series tonales y superposiciones, información arqueológica 

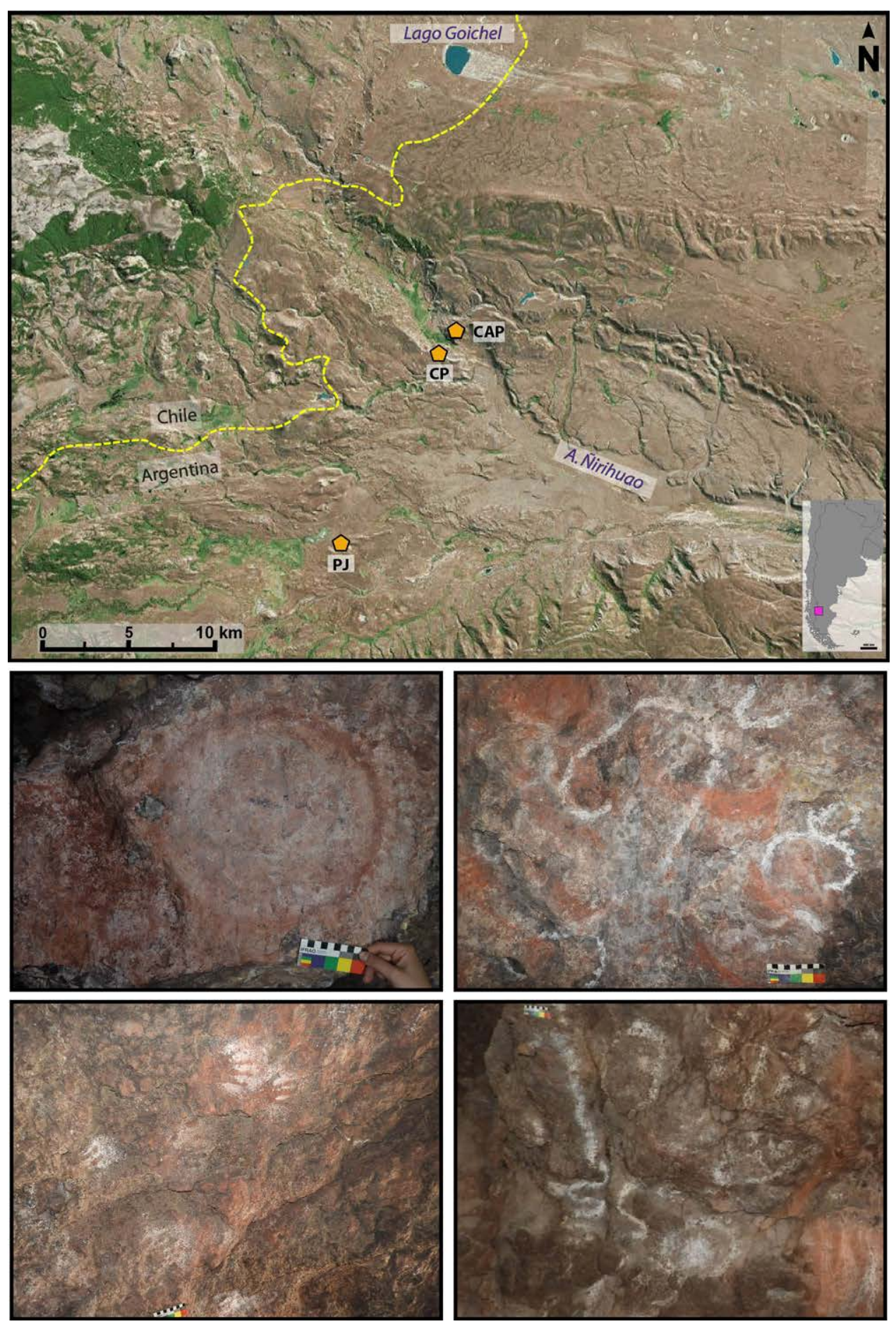

Figura 1. Sitios arqueológicos bajo estudio y ejemplos de motivos registrados en el área.

contextual e indicadores estilísticos. Para la determinación de actividades potencialmente llevadas a cabo en los sitios, se revisaron artefactos recuperados en estratigrafía o alrededores y se analizaron las características espaciales. Para entender relaciones entre sitios (microescala), se realizaron comparaciones entre los resultados obtenidos a escala de sitio. Por último, para atender una escala mesoregional, se utilizaron datos bibliográficos disponibles para otras áreas del sudoeste de Chubut, Aysén (Chile) y noroeste de Santa Cruz.

La muestra analizada consistió en 913 motivos, en su totalidad pinturas. La mayoría se encuentra en muy mal estado de conservación. Se destaca la variedad de motivos registrados (numerosos tipos de abstractos y figurativos, como negativos 


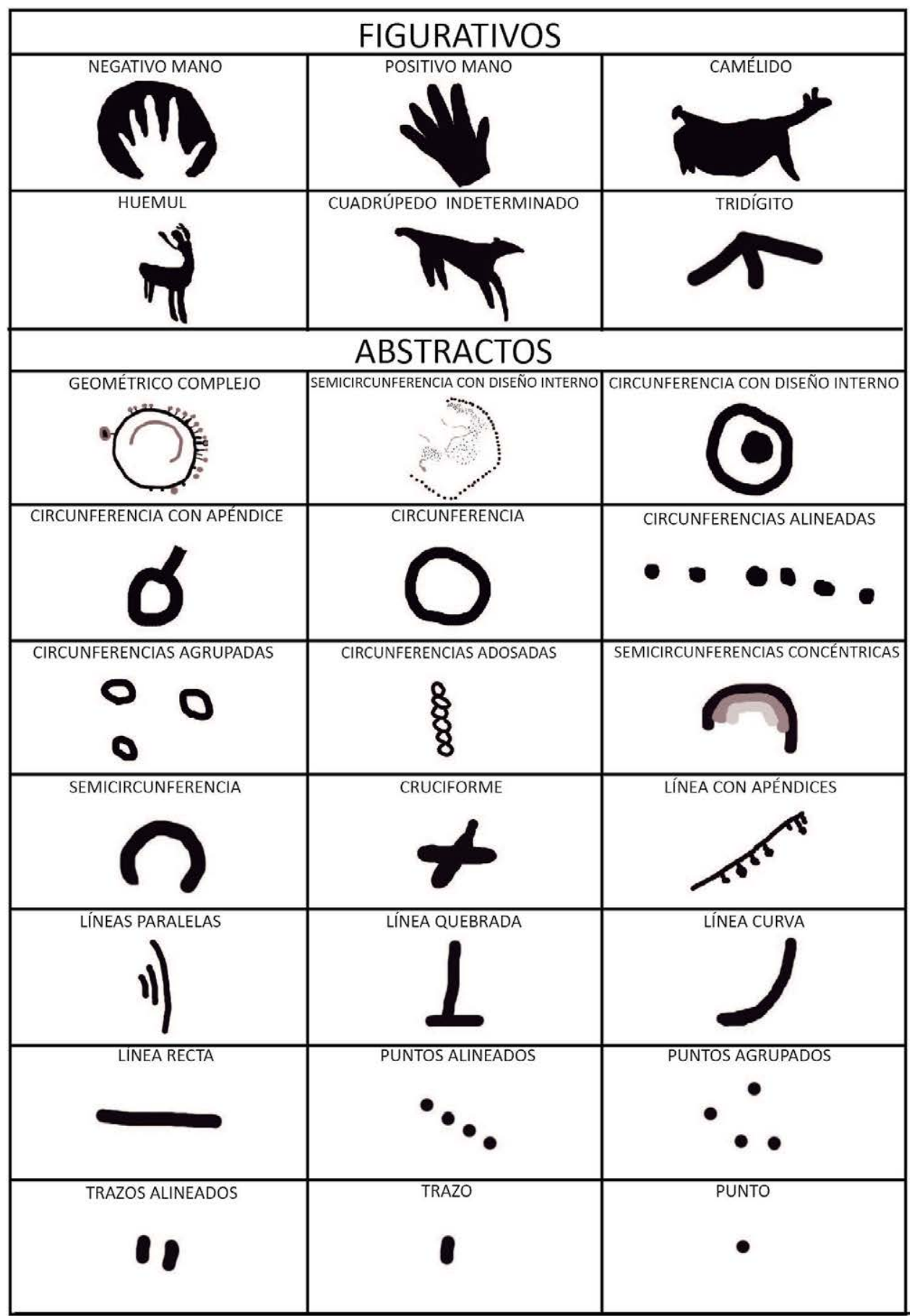

Figura 2. Tipología de motivos prehispánicos relevados en Aldea Beleiro.

de mano, camélidos, huemules, etc.) (Figura 2), de modos de aplicación de pintura, de series tonales y de superposiciones.

En cuanto a lo cronología, a partir de las variables analizadas se determinó que la confección de pinturas en el área data al menos desde el Holoceno medio, aunque la presencia en estratigrafía de elementos potencialmente relacionados con el tratamiento de pigmentos advierten sobre la posibilidad de que la realización de motivos se haya dado desde el Holoceno temprano (presencia en CP1 de pigmentos naturales a lo largo de la secuencia estratigráfica y especímenes de Artiodactyla con tinción en tonos rojos, cuyo ejemplar más temprano se recuperó de una capa fechada en ca. 8000 años AP).

Con respecto a las actividades que habrían tenido lugar en los sitios, puede señalarse que, si bien la asociación con 
tareas domésticas pudo constatarse en un caso (CP1), otros indicadores (por ejemplo, cuestiones espaciales y tecnológicas) permiten pensar que la producción y uso de pinturas, contrario a lo que ha sido postulado para otras áreas, estuvo relacionado con grupos reducidos de personas y actividades planificadas.

El análisis a escala microregional mostró que en $\mathrm{CP}$ se concentra más del $80 \%$ de los motivos registrados en Aldea Beleiro y se encuentra representada prácticamente la totalidad de tipos de motivos documentados. Por otro lado, la presencia tanto en CP como en CAP de los mismos grupos cronológicos podría indicar un uso relativamente sincrónico de estos espacios.

El análisis mesoregional realizado permitió vincular los sitios de Aldea Beleiro principalmente con la región vecina de Aysén y el noroeste de Santa Cruz. Se destaca que esta área podría dar cuenta del caso más septentrional de presencia de camélidos B1. Esto indica la necesidad de integrar esta zona a las dinámicas de circulación humana planteadas para el Holoceno medio a partir de estas representaciones (Aschero, 1993; Aschero e Isasmendi 2018). La presencia a lo largo de toda la estratigrafía de obsidiana de Pampa del Asador y de Río Cisnes (capa 6), así como la similitud tecnológica observada con los artefactos líticos de los sitios cercanos de Aysén, refuerzan esta idea (Castro Esnal, Pérez de Micou y Casanueva, 2017; Castro Esnal, Pérez de Micou y Stern, 2017). También cabe señalar que, a pesar de la presencia conspicua de motivos asociados al "Estilo de Grecas" (Menghin, 1957) en sitios arqueológicos del sudoeste de Chubut, este no ha sido registrado en el área.

En suma, este trabajo presentó nuevos datos sobre pinturas rupestres en una región que carecía de esta información. Se realizó un análisis exhaustivo de la dimensión visual del arte, que puso un énfasis importante en el procesamiento digital de la muestra de imágenes y permitió abrir una serie de nuevos interrogantes, por ejemplo:

" La redundancia observada en el uso de colores podría compararse con otras líneas de evidencia, como la tecnología lítica, que señala el aprovechamiento continuo en el tiempo de las mismas materias primas (Castro Esnal et al. 2016; Castro Esnal, Pérez de Micou y Casanueva, 2017, entre otros). Esto constituye un disparador para indagar acerca de la dimensión tecnológica de las pinturas y el entendimiento acerca de todo su proceso productivo (Fiore, 2006, 2007, 2009, r).

» Teniendo en cuenta la importancia del área para el estudio del poblamiento temprano del So de Chubut (Castro Esnal, Pérez de Micou y Casanueva, 2017), la presencia de indicadores de tecnologías relacionadas con el uso de pigmentos en capas fechadas alrededor de los 8000 años cal. AP constituyen una oportunidad para abordar el rol cumplido por esta materialidad desde momentos de exploración (Carden, Miotti y Blanco, 2018).

»Para los momentos tardíos, se constató la presencia de un componente que puede considerarse característico de la zona. Esto, sumado a la ausencia de representaciones de tipo "grecas", invita a problematizar acerca de la distribución de estos motivos.

» El abordaje de las representaciones de momentos históricos mostró potencial para profundizar acerca de las dinámicas recientes de ocupación del espacio (López, Lanza, Díaz y Marcos, 2014; Podestá, Rolandi, Re, Falchi y Damiani, 2006).

»Este trabajo permite retomar la hipótesis acerca de la vinculación entre caminos y arte rupestre (Castro Esnal, 2014), especialmente a partir del sitio CP, emplazado en un espacio que funciona como vía de comunicación natural entre el bosque y la estepa.

\section{Referencias citadas}

»Aschero, C. (1988). Pinturas rupestres, actividades y recursos naturales; un encuadre arqueológico. En H. D. Yacobaccio, L. A. Borrero, L. C. García, G. G. Politis, C. A. Aschero y C. Bellelli (Eds.), Arqueología Contemporánea Argentina. Actualidad y perspectivas (pp. 109-145). Buenos Aires: Ediciones Búsqueda.

" Aschero, C. (1993). ¿Adónde van esos guanacos? En por J. Gómez Otero (Ed.), Arqueología. Solo Patagonia. Ponencias de las Segundas Jornadas de Arqueología de la Patagonia (pp. 153-162). Puerto Madryn: Centro Nacional Patagónico. Consejo Nacional de Investigaciones Científicas y Técnicas.

» Aschero, C. (2012). Las escenas de caza en Cueva de las Manos: una perspectiva regional (Santa Cruz, Argentina). En J. Clottes (Ed.), L'Art Pléistocène dans le Monde / Pleistocene Art of the World / Arte Pleistoceno en el Mundo, Actes du Congrès IFRAO (pp. 807-823). Tarascon-surAriège: $N^{\circ}$ Spécial de Préhistoire, Art et Sociétés, Bulletin de la Société Préhistorique Ariège-Pyrénées.

" Aschero, C. e Isasmendi, M. V. (2018). Arte rupestre y demarcación territorial: el caso del grupo estilístico B1 en el área Río Pinturas (Santa Cruz, Argentina). Revista del Museo de La Plata, 3, 112-131.

»Carden, N., Miotti, L. y Blanco, R. (2018). Nuevos datos sobre las pinturas rupestres de Los Toldos (Santa Cruz, Argentina): bases para un enfoque comparativo en Patagonia Meridional. Latin American Antiquity, 29 (2), 293-310.

"Castro Esnal, A. (2014). Camino y Piedra. Rutas Indígenas y Arqueología en la Provincia de Chubut. Buenos Aires: Fundación de Historia Natural Félix de Azara.

» Castro Esnal, A., Casanueva, M. L., Sacchi, M. y Pérez de Micou, C. (2016). Estudios arqueológicos en Aldea Beleiro, So del Chubut, Argentina. Desde el primer poblamiento 
hasta el siglo XX. Revista del Museo de Antropología, 9(1), 7-12.

» Castro Esnal, A.; Pérez de Micou, C. y Casanueva, M. L. (2017). Early Holocene occupation of the forest-steppe ecotone of Southern South America: evidence from Casa de Piedra de Roselló Cave (Chubut, Patagonia Argentina). PaleoAmerica, 3, 1-7.

» Castro Esnal, A., Pérez de Micou, C. y Stern, C.R. (2017). Obsidian provenance and transport in central Patagonia (Chubut, Argentina). From the Early Holocene to historical contexts. Trabajo presentado en el 11th Symposium on Knappable Materials, Buenos Aires, Argentina.

》Dincauze, D. F. (2000). Concepts for paleoenvironmental reconstruction. En Environmental Archaeology: Principles and Practice. Cambridge: Cambridge University Press.

» Fiore, D. (2006). Poblamiento de imágenes: arte rupestre y colonización de la Patagonia. Variabilidad y ritmos de cambio en tiempo y espacio. En D. Fiore y M. M. Podestá (Eds.), Tramas en la Piedra. Producción y Usos del Arte Rupestre (pp. 43-62). Buenos Aires: World Archaeological Congress, Sociedad Argentina de Antropología, Asociación de amigos del Instituto Nacional de Antropología.

" Fiore, D. (2007). The economic side of rock art: concepts on the production of visual images. Rock Art Research, 24(2), 149-160.

"Fiore, D. (2009). La materialidad del arte. Modelos económicos, tecnológicos y cognitivo-visuales. En R. Barberena, K. Borrazzo y L. A. Borrero (Eds.), Perspectivas Actuales en Arqueología Argentina (pp. 121-154). Buenos Aires: Instituto Multidisciplinario de Historia y Ciencias Humanas (IMHICIHU), CONICET.

"Gradin, C. (1978). Algunos aspectos del análisis de las manifestaciones rupestres. Revista del Museo Provincial de Neuquén, 1, 120-137.

» Gradin, C., Aschero, C. y Aguerre, A. (1976). Investigaciones arqueológicas en la Cueva de las Manos. Estancia Alto Río Pinturas (Prov. de Santa Cruz). Relaciones de la Sociedad Argentina de Antropología, X, 3-52.

" Gradin, C., Aschero, C. y Aguerre, A. M. (1979). Arqueología del área Río Pinturas. Relaciones de la Sociedad Argentina de Antropología, XIII, 183-227.

» Gutiérrez, L. A. y Castro Esnal, A. (2018). Análisis preliminar de las representaciones rupestres de Casa de Piedra de Roselló, Aldea Beleiro, So de Chubut. Comechingonia, Revista de Arqueología Chilena, 21(2), 401-411.

» Gutiérrez L. A., Castro Esnal, A., Ronco, F. E., Casanueva, M. L. y Pérez de Micou, C. B. (2018). Rupestrian representations of historical times: continuities and ruptures in Southwest
Chubut, Argentinean Patagonia. En 20th International Rock Art Congress IFRAO. Standing on the Shoulders of Giants/ Sulle spalle dei giganti. 20th International Rock Art Congress IFRAO 2018. Book of Abstract, (p. 558). Capo di Ponte (BS): Edizioni del Centro Camuno di Studi Preistorici.

» Gutiérrez, L. A y Pérez de Micou, C. (2017). Primeros resultados del análisis del arte rupestre del sitio Casa de Piedra de Roselló, Localidad de Aldea Beleiro, SO Chubut. En J. Gómez Otero (Ed.), X Jornadas de Arqueología de Patagonia. Libro de Resúmenes (p. 102). Puerto Madryn: Centro Nacional Patagónico (CENPAT), CONICET.

» Hernández Llosas, M. I. (1985). Diseño de investigación para representaciones rupestres. En PROINDARA. Programa de Investigación y Documentación de Arte Rupestre Argentino (pp. 9-65). Buenos Aires: Fundación para la Educación, la Ciencia y la Cultura (FECIC).

»Lenssen-Erz, T. (2004). The landscape setting of rockpainting sites in the Brandberg, Namibia: infrastructure, Gestaltung, use and meaning. En C. Chippindale y G. Nash (Eds.) Pictures in Place - The Figured Landscapes of RockArt, (pp.131-150). Cambridge: Cambridge University Press.

» Loendorf, L. (2001). Rock art recording. En D. Whitley (Ed.), Handbook of Rock Art Research, (pp. 55-79). Walnut Creek: AltaMira Press.

» López M. A., Lanza, A. Díaz, V. C. y Marcos, M. S. (2014). Ocumazo en imágenes. Revista Chilena de Antropología Visual, 24, 99-127.

» Menghin, O. (1957). Estilos del arte rupestre de Patagonia. Acta Praehistórica, 1, 57-87.

»Pérez de Micou, C., Castro Esnal, A. y Sacchi, M. (2013). Estudios preliminares en el sitio Casa de Piedra, Estancia Roselló, sudoeste de Chubut. En A. F. Zangrando, R. Barberena, A. Gil, G. Neme, M. Giardina, L. Luna, C. Otaola, S. Paulides, L. Salgán y A. Tivoli (Eds.) Tendencias TeóricoMetodológicas y Casos de Estudio en la Arqueología de la Patagonia, (pp. 213-218). San Rafael: Museo de Historia Natural de San Rafael.

» Podestá, M. M., Rolandi, D., Re, A., Falchi, M. P. y Damiani, O. (2006). Arrieros y marcas de ganado: expresiones de arte rupestre de momentos históricos en el desierto de Ischigualasto. En D. Fiore y M.M. Podestá (Eds.) Tramas en la Piedra. Producción y Usos del Arte Rupestre, (pp. 169-190). Buenos Aires: World Archaeological Congress, Sociedad Argentina de Antropología, Asociación de amigos del Instituto Nacional de Antropología.

» Re, A. (2010). Representaciones rupestres en mesetas altas de la provincia de Santa Cruz. Circulación de información en espacios de uso estacional. (Tesis Doctoral inédita), Universidad de Buenos Aires, Argentina. 